\title{
Pneumomediastinum caused by hypopharyngeal perforation during endoscopic ultrasound-guided fine-needle aspiration
}

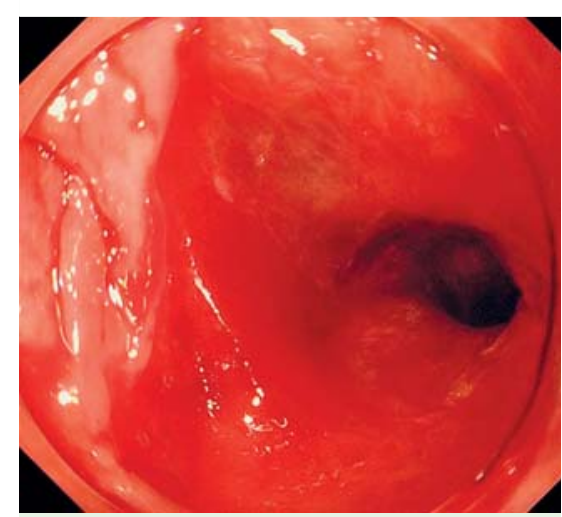

Fig. 1 Upper gastrointestinal endoscopy showing a perforation that had occurred on the inside of the left hypopharyngeal entrance.

A 78-year-old man presented with a major complaint of back pain. A contrastenhanced computed tomography (CT) scan showed a 2-cm hypovascular, irregular, tumorous lesion in the body of the pancreas that was invading the celiac, splenic, and common hepatic arteries. Endoscopic ultrasound-guided fine-needle aspiration (EUS-FNA) was planned.
First, an upper gastrointestinal endoscopy was performed, during which the endoscope (GIF-H290Z; Olympus Medical Systems, Tokyo, Japan) passed easily through the left hypopharynx. The endoscope for the EUS-FNA (GF-UCT260; Olympus Medical Systems, Tokyo, Japan) was then carefully inserted, but it was difficult to pass the scope into the esophagus. After two or three attempts, a sense of breaking through the mucosa was felt via the scope, so upper gastrointestinal endoscopy was carried out again. It was discovered that a perforation had occurred on the inside of the left hypopharyngeal entrance ( $\bullet$ Fig. 1 ). The scope was withdrawn, and a further CT scan showed a pneumomediastinum and intraperitoneal free air ( $\bullet$ Fig. 2 a).

Although emergency surgery was considered, the patient's general condition was stable, and conservative therapy was therefore chosen. The patient was started on meropenem and was forbidden to take food and drink for 7 days, after which a CT scan was performed again, which this time indicated significant improvement
( $\nabla$ Fig.2b). The patient was allowed to start eating again and no relapse occurred. EUS has been used for many years in both diagnosis and treatment. A few cases of hypopharyngeal perforation during EUS have been reported [1]. The rate of cervical esophageal perforation is reported to be $0 \%-0.03 \%[2,3]$. Perforation of the esophagus is associated with a mortality rate of $2 \%-36 \%$, with early identification and management having been shown to decrease the associated morbidity and mortality [4].

This is a first report to show that pneumomediastinum caused by hypopharyngeal perforation during EUS-FNA can be treated conservatively. If the patient's condition is stable, we would choose conservative treatment for hypopharyngeal perforation; however, the option of surgical treatment should the patient's condition worsen must not be lost.

\section{Endoscopy_UCTN_Code_CPL_1AL_2AB}

\section{Competing interests: None}

Tomoya lida ${ }^{1}$, Takeya Adachi ${ }^{1}$, Suguru Nakagaki ${ }^{1}$, Takashi Yabana', Akira Goto ${ }^{1}$, Yoshihiro Kondo ${ }^{1}$, Hiroshi Nakase ${ }^{2}$

${ }^{1}$ Department of Gastroenterology, Otaru City General Hospital, Otaru, Japan

2 Department of Gastroenterology and Hepatology, Sapporo Medical University, Sapporo, Japan
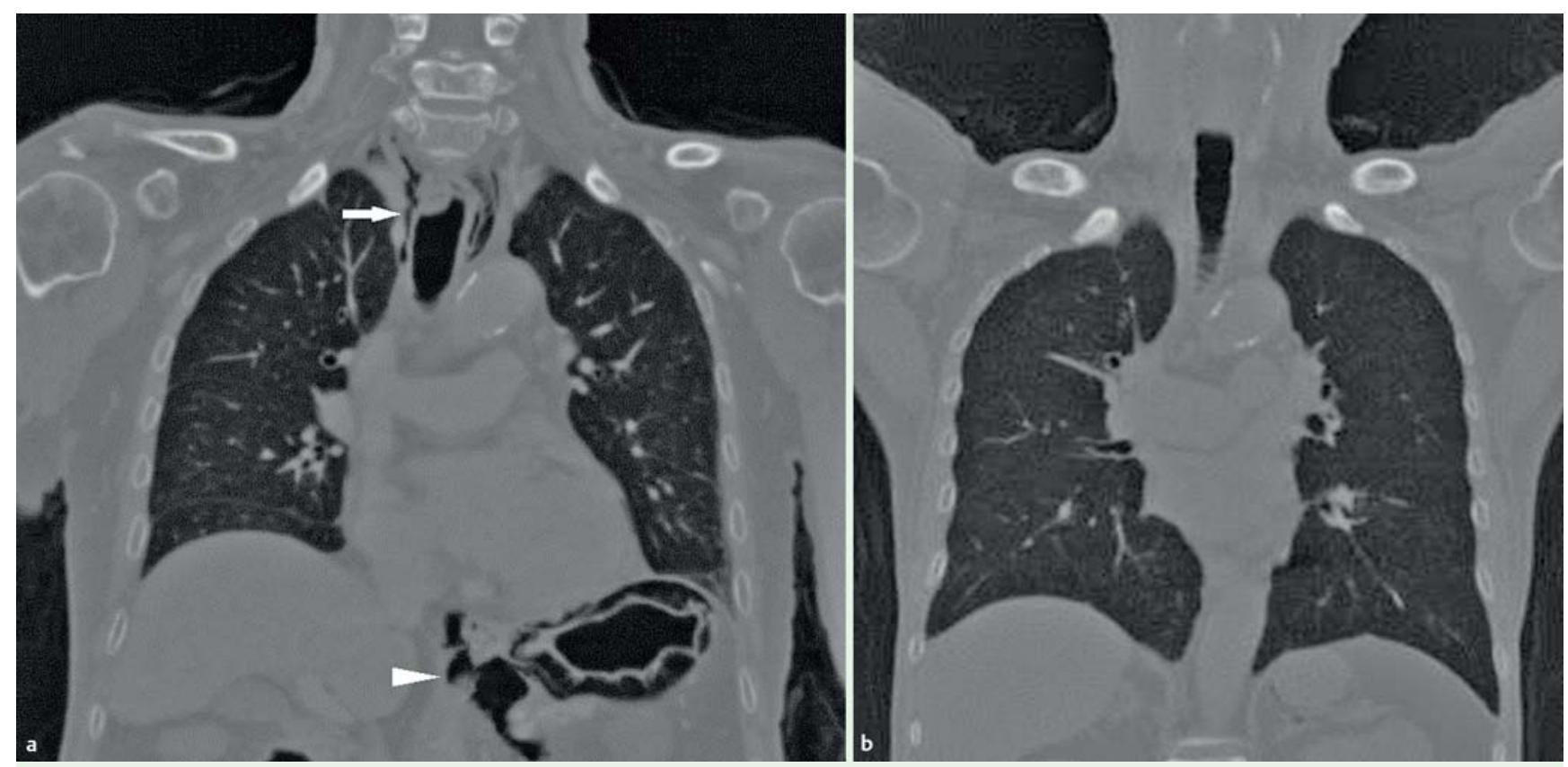

Fig. 2 Computed tomography (CT) scans done: a after the hypopharyngeal perforation was noted on endoscopy, showing a pneumomediastinum (arrow) and intraperitoneal free air (arrow head); $\mathbf{b} 7$ days later, showing significant improvement with the pneumomediastinum and intraperitoneal free air having almost disappeared. 


\section{References}

1 Sharma N, Jindal M, Mahon B et al. Hypopharyngeal perforation during endoscopic ultrasound treated by primary repair. Head Neck 2011; 33: 756-758

2 Das A, Sivak MV Jr, Chak A. Cervical esophageal perforation during EUS: a national survey. Gastrointest Endosc 2001; 53: 599-602

3 Mahnke D, Chen YK, Antillon MR et al. A prospective study of complications of endoscopic retrograde cholangiopancreatography and endoscopic ultrasound in an ambulatory endoscopy center. Clin Gastroenterol Hepatol 2006; 4: 924-930

4 Abbas G, Schuchert MJ, Pettiford BL et al. Contemporaneous management of esophageal perforation. Surgery 2009; 146: 749-755
Bibliography

Dol http://dx.doi.org/

10.1055/s-0042-108574

Endoscopy 2016; 48: E206-E207

(c) Georg Thieme Verlag KG

Stuttgart · New York

ISSN 0013-726X
Corresponding author

Tomoya lida, MD

Department of Gastroenterology

Otaru City General Hospital

1-1 1-chome, Wakamatu-cho, Otaru

Hokkaido, 047-8550

Japan

Fax: +81-134-326424

tomoya.iida.0306@gmail.com 